\title{
Replicative Homeostasis: A fundamental mechanism mediating selective viral replication and escape mutation Richard Sallie*
}

\author{
Address: Suite 35, 95 Monash Avenue, Nedlands, Western Australia, Australia \\ Email: Richard Sallie* - sallier@mac.com \\ * Corresponding author
}

Published: II February 2005

Virology Journal 2005, 2:10 doi:10.1186/1743-422X-2-10

This article is available from: http://www.virologyj.com/content/2/1//0

(C) 2005 Sallie; licensee BioMed Central Ltd.

This is an Open Access article distributed under the terms of the Creative Commons Attribution License (http://creativecommons.org/licenses/by/2.0), which permits unrestricted use, distribution, and reproduction in any medium, provided the original work is properly cited.
Received: 23 January 2005

Accepted: II February 2005

\begin{abstract}
Hepatitis C (HCV), hepatitis B (HBV), the human immunodeficiency viruses (HIV), and other viruses that replicate via RNA intermediaries, cause an enormous burden of disease and premature death worldwide. These viruses circulate within infected hosts as vast populations of closely related, but genetically diverse, molecules known as "quasispecies". The mechanism(s) by which this extreme genetic and antigenic diversity is stably maintained are unclear, but are fundamental to understanding viral persistence and pathobiology. The persistence of HCV, an RNA virus, is especially problematic and HCV stability, maintained despite rapid genomic mutation, is highly paradoxical. This paper presents the hypothesis, and evidence, that viruses capable of persistent infection autoregulate replication and the likely mechanism mediating autoregulation - Replicative Homeostasis - is described. Replicative homeostasis causes formation of stable, but highly reactive, equilibria that drive quasispecies expansion and generates escape mutation. Replicative homeostasis explains both viral kinetics and the enigma of RNA quasispecies stability and provides a rational, mechanistic basis for all observed viral behaviours and host responses. More importantly, this paradigm has specific therapeutic implication and defines, precisely, new approaches to antiviral therapy. Replicative homeostasis may also modulate cellular gene expression.
\end{abstract}

\section{Background}

\section{Disease burden}

Hepatitis C (HCV), HBV and HIV are major causes of premature death and morbidity globally. These infections are frequently life-long; Hepatitis viruses may result in progressive injury to the liver and cirrhosis, and death from liver failure, or hepatocellular carcinoma, while HIV causes progressive immune depletion and death from the acquired immunodeficiency syndrome (AIDS). Together, these infections cause millions of premature deaths annually, predominantly in "developing" countries. Other viruses replicating via RNA intermediaries cause similar morbidity among domestic and wild animal populations.
While education, public health measures and vaccination (for HBV) have resulted in significant progress in disease control, therapy of established viral infection remains unsatisfactory.

\section{Viral replication}

RNA viruses and retroviruses replicate, at least in part, by RNA polymerases $\left(\mathrm{RNA}_{\mathrm{pol}}\right)$, enzymes that lack either fidelity or proofreading function [76]. During replication of hepatitis $\mathrm{C}$ HCV or HIV each new genome differs from the parental template by up to ten nucleotides [61] due to $\mathrm{RNA}_{\text {pol }}$ infidelity that introduces errors at $\sim 1 \times 10^{-5}$ mutations / base RNA synthesised. 


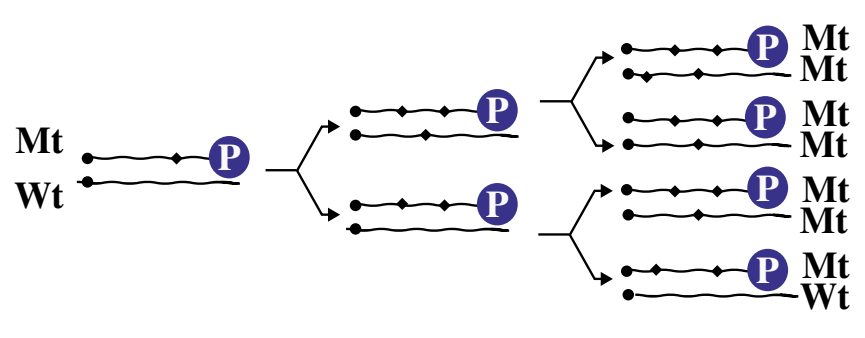

$\mathrm{G}_{1}$

$G_{2}$

G3

Figure I

Effect of RNApol fidelity on replication. Each replication cycle may produce either wild-type $(\mathrm{Wt})$ or variant $(\mathrm{Mt})$ copies of parental template in a ratio determined by polymerase fidelity. If HCV RNA $A_{p o l} M_{u}$ is $10^{-5}$ mutations per base RNA synthesized, Mt:Wt ratio at $G_{1}$ is $\sim 9: 1$, by $G_{3}$ unmutated parental genome is $6.8 \times 10^{-4}$ of total virus population, and by $\mathrm{G}_{20} 7.5 \times 10^{-22}$

Viruses replicate by copying antigenomic intermediate templates and hence obey exponential growth kinetics, such that $[\mathrm{RNA}]_{\mathrm{t}}=[\mathrm{RNA}]_{(\mathrm{t}-1)} \mathrm{e}^{\mathrm{k}}$, where $[\mathrm{RNA}]_{\mathrm{t}}$ is virus concentration at time $(\mathrm{t})$ and $\mathrm{k}$ a growth constant. However, because of $\mathrm{RNA}_{\text {pol }}$ infidelity, wild-type $(\mathrm{wt})$ virus will accumulate at $\left[\mathrm{RNA}_{\mathrm{wt}}\right]_{\mathrm{t}}=\left[\mathrm{RNA}_{\mathrm{wt}}\right]_{(\mathrm{t}-1)} \bullet(1-\rho) \bullet \mathrm{K}_{1}$ and variant forms (mt) at $\left[\mathrm{RNA}_{\mathrm{mt}}\right]_{\mathrm{t}} \approx\left(\left[\mathrm{RNA}_{\mathrm{wt}}\right]_{(\mathrm{t}-1)} \bullet \rho+\left[\mathrm{RNA}_{\mathrm{mt}}\right]_{(\mathrm{t}-}\right.$ $\left.{ }_{1)}\right) \bullet K_{1}$, where $\rho$ is the probability of mutation during replication and $K_{1}=e^{k}$. Therefore, while wild-type virus predominates early, replication (and intracellular accumulation) of variant virus and viral proteins will accelerate (in a ratio of $\left(\left[\mathrm{RNA}_{\mathrm{wt}}\right]_{(\mathrm{t}-1)} \bullet \rho+\left[\mathrm{RNA}_{\mathrm{mt}}\right]_{(\mathrm{t}-1)}\right) /$ $\left[\mathrm{RNA}_{\mathrm{wt}} \mathrm{t}_{(\mathrm{t}-1)} \bullet(1-\rho)\right.$ compared to wild type) and variant viral RNAs will rapidly predominate (Figure 1). Mutations progressively accumulate in RNA viruses [17] and ultimately variant RNAs and proteins, if variant RNAs are translated, will become dominant. It is also likely some variant viral proteins will resist cellular trafficking, further accelerating the intracellular accumulation of variant forms relative to wild type.

\section{The paradox of quasispecies stability}

Two fundamental problems critical to understanding RNA virus quasispecies biology arise because of RNA polymerase infidelity and the mode of viral replication:

\section{I: Replication kinetics}

Hepatitis C, HIV, and HBV and other viruses, have broadly similar kinetics (Figure 2); initial high level viral replication that rapidly declines to relatively constant lowlevel viraemia $[11,12]$, typically $2-3$ logs lower than at peak, for prolonged periods, a kinetic profile attributed to "immune control" [12]. However, immune control is a

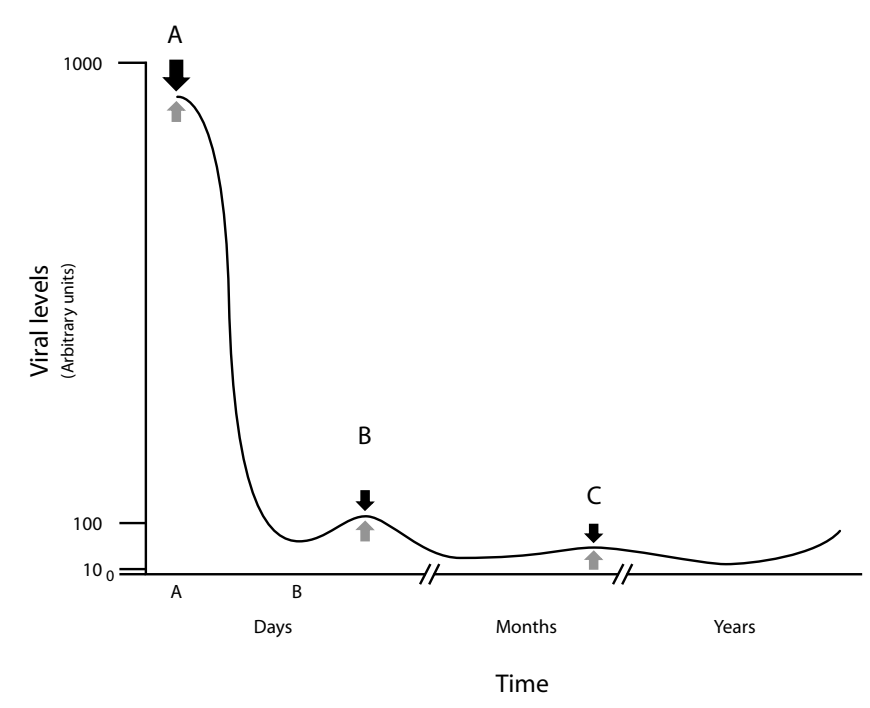

Figure 2

Viral kinetic paradox. Viral replication kinetics (-). If host factors ( $I_{c}$, black arrows) reduce viral replication acutely (point $A)$, then they must exceed viral forces $\left(V_{e}\right.$, grey arrows). At equilibrium (e.g. points $B$ or $C$ ) host forces must balance viral forces; $I_{c}$ must therefore fall by a factor of $10^{2-3}$ from $A$.

conceptually problematic explanation for the initial decline in viral load; For example; why would potent host responses (of whatever type; humoral, cell mediated or intracellular immunity, or any combination thereof), having reduced viral load and antigenic diversity by a factor of $10^{2-3}$ within days, falter once less than $1 \%$ of virus remains?

Formally

1. Assume immune mechanisms reduce initial viral replication.

2. Let $I_{c(t)}$ represent the immune forces favouring viral clearance and $\mathrm{V}_{\mathrm{e}(\mathrm{t})}$ viral forces promoting quasispecies expansion pressures at time $(\mathrm{t})$.

3. Assume immune pressures $I_{c}$ required to clear virus are proportional to viral concentration $[\mathrm{V}]$, that is; $\mathrm{V}_{\mathrm{e}} \propto[\mathrm{V}]$ (or $\mathrm{V}_{\mathrm{e}}=\mathrm{k}_{\mathrm{e}}[\mathrm{V}]$ where $\mathrm{k}_{\mathrm{e}}$ is some constant), so that $\mathrm{I}_{\mathrm{c}}$ required to clear one viral particle $I_{c(1)}$ is less than that $I_{c}$ required to clear 10 viral particles $\mathrm{Ic}_{(10)}$.

4. At equilibrium (e.g. time points B or C, Figure. 2) immune clearance pressures approximate viral antigenic expansion pressures: $\mathrm{I}_{\mathrm{c}(\mathrm{b} \text { or } \mathrm{c})} \approx \mathrm{V}_{\mathrm{e}(\mathrm{b} \text { or } \mathrm{c})} . \quad$ Eq. 1 
5. If $\mathrm{I}_{\mathrm{c}}$ causes the reduced viral load seen between time $\mathrm{A}$ and time $\mathrm{B}$ or $\mathrm{C},\left[\mathrm{V}_{\mathrm{e}(\mathrm{a})}\right] \Rightarrow\left[\mathrm{V}_{\mathrm{e}(\mathrm{b} \text { or } \mathrm{c})}\right]$, then immune clearance pressures must exceed viral expansion pressures at that time i.e. $\mathrm{I}_{\mathrm{c}(\mathrm{a})}>\mathrm{V}_{\mathrm{e}(\mathrm{a})}$. Eq.2

6. As viral antigenic expansion pressures at time A exceed those at time (B or C) by $10^{2-3}\left[\mathrm{~V}_{(\mathrm{a})}\right] \approx\left[\mathrm{V}_{(\mathrm{b} \text { or } \mathrm{c})}\right] \bullet 10^{2-3}$, and $\mathrm{I}_{\mathrm{c}(\mathrm{b} \text { or } \mathrm{c})}=\mathrm{V}_{\mathrm{e}(\mathrm{b} \text { or } \mathrm{c})}$ then immune clearance pressures at time A exceed those at time (B or C) by $10^{2-3} \mathrm{I}_{\mathrm{c}(\mathrm{a})}>\mathrm{I}_{\mathrm{c}(\mathrm{b} \text { or } \mathrm{c})}{ }^{\bullet} 10^{2-}$ 3 . That is, immune pressures fall by $10^{2-3}$ between time $\mathrm{A}$ and $\mathrm{B}$ or $\mathrm{C}$, (Figure. 2).

\section{Prompting}

i) Why, and by what mechanism, would immune forces, or any other host defense mechanisms, fall by $10^{2-3}$ over days between time A and B or C?

There is, of course, no evidence immune pressures fall, and very considerable evidence both antibody and adaptive $\mathrm{T}$ cell responses are increasing when viral replication is falling $[5,12]$. These facts are irreconcilable with the notion that immune or other any host mechanisms control initial viral replication and strongly suggest immune or any other host mechanism(s) are not the primary reason viral load falls initially. Further, as down-regulation of viral replication frequently occurs prior to development of neutralising antibody, in the absence of any demonstrable antiviral antibody, or T-cell responses [25,41], and without lysis of infected cells [25], it is difficult to argue, with any conviction, that either humoral or cellular immune responses primarily cause reduced viral replication. Evidence that prior HCV infection does not confer protective immunity against either heterologous HCV infection in chimpanzee [22]or either homotypic [33] or heterotypic [32] human reinfection further undermines the paradigm of "immune control". Inhibition of immune or other host mechanisms is an untenable explanation of this massive apparent fall in immune clearance pressures; if occurred to any degree, an increase, rather than the observed decrease, in viremia would result. In the absence of a rational host mechanism consistent with observed viral kinetic data, the ineluctable conclusion is that non-host (i.e. viral) mechanisms (i.e. viral auto regulation) must be operative.

Chronic viral persistence raises other issues; At steady state (e.g. points B or C, Figure. 2), the rate of HIV and HCV production is estimated at $10^{10}$ molecules / day $[11,29,52,57]$ while HBV production may be $10^{11}$ molecules/day resulting in an average viral load of $10^{10}$ molecules/person [52,57]. However, during peak replication virus production may $10^{2-3}$ times the basal rate $[11,12]$, indicating enormous reserve replicative capacity. As basal viral replication is clearly sufficient for long-term stability, and kinetic analysis suggests viral, rather than host, factors control viral replication, the following questions are posed: When challenged, how do viruses "sense" the threat and by what mechanism do they modulate replication in response?

\section{Problem 2: Mutation rate}

The stability of RNA viral quasispecies poses a major problem: During viral replication the copied genome may either identical to or a variant of parental template (Figure. 1). The probability ( $\rho$ ) of a mutation occurring during replication is a function of polymerase fidelity; During one replication cycle $\rho=\left(1-\left(1-M_{\mu}\right)^{n}\right)$, where $\left(M_{\mu}\right)$ is mutation rate and $(\mathrm{n})$ genome size. Hepatitis $\mathrm{C}(\mathrm{a} \sim 9200 \mathrm{bp}$ RNA virus) RNA $_{\text {pol }}$ introduces mutation at $10^{-5}$ substitutions/base, $\rho \approx 0.912$. However, for multiple $(\theta)$ replications cycles, $\rho=\left(1-\left(1-M_{\mu}\right)^{n}\right)^{\theta}$. After 20 replication cycles, occurring in $<7$ days in most patients $[52,57]$, the probability of any original genome remaining un-mutated is $\rho_{\mathrm{o}} \approx 7.5 \times 10^{-22}$, meaning effective loss of sequence information, an outcome that should cause quasispecies extinction [16]. Persistence of stable RNA viral quasispecies is, therefore, highly paradoxical [18]. This "theoretical impossibility" of RNA quasispecies stability suggests either a) the consistently reported rates of RNA ${ }_{\text {pol }}$ infidelity are incorrect (which, even if true, would only delay quasispecies extinction; if $M_{\mu}=10^{-10}, \rho_{\mathrm{o}}<10^{-40}$ within 100 days etc.) or b) that innate viral mechanism(s) control RNA $_{\text {pol }}$ fidelity and mediate selective replication of consensus sequence genomes. Thus, rates of viral mutation are tightly constrained by the necessity to retain sequence information. On the other hand, overly faithful template replication will restrict antigenic diversity, rendering virus susceptible to immune destruction and unresponsive to ongoing cellular changes. The necessity to retain sequence information by adequate replicative fidelity, and the later requirements (in terms of replicase $\Rightarrow \mathrm{RNA}_{\mathrm{pol}}$ evolution) of viruses to access cells via evolving cell receptors and evade host defence mechanisms, has placed constraints on replicase $\left(\mathrm{RNA}_{\mathrm{pol}}\right)$ function that dictate polymerase fidelity must be tightly, and dynamically, controlled (Figure 3a).

\section{Evolutionary constraints on viral replication}

Optimal viral replication is a compromise between maximising host-to-host viral transmission at each host contact versus maximising transmission at sometime during the host's life: Uncontrolled, exponential growth, as might result from the mode of viral replication, would cause rapid cell lysis, host death and a reduced likelihood of stable host-to-host transmission, a prerequisite for viral survival on an evolutionary timescale. While maximising the probability of host-to-host transmission at each contact, high-level viral replication increases the probability of host disease, thus reducing opportunity for transmission long term. Contrariwise, adverse viral outcomes may 


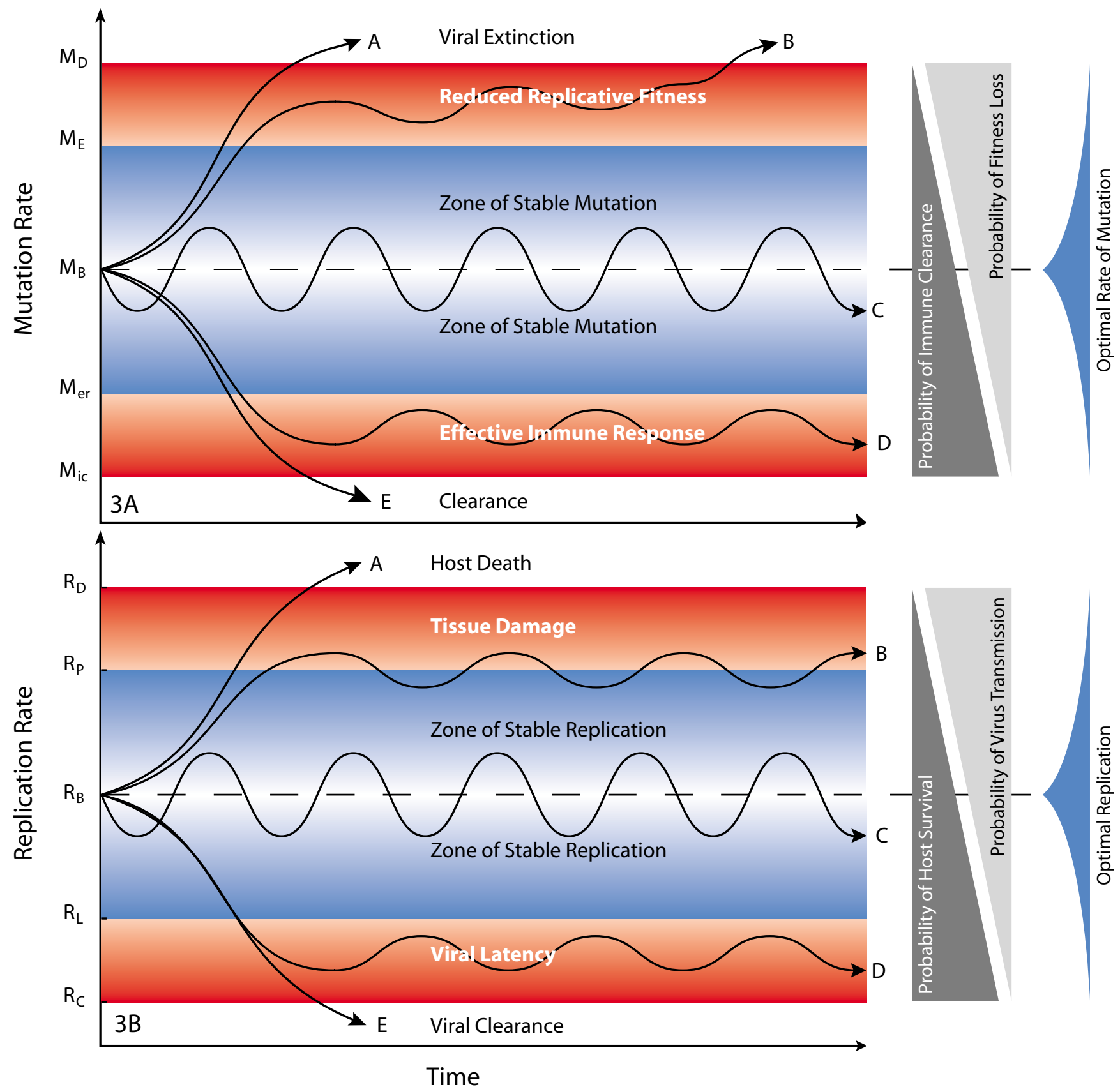

\section{Figure 3}

a. Constraints on viral mutation. Inadequate polymerase fidelity will cause loss of sequence information and quasispcies extinction $(A, B)$, while inadequate viral mutation will result in immune recognition and viral clearance $(D, E)$. Viral persistence requires polymerase fidelity responsive to the host environment $(C)$. 3b. Constraints on viral replication. Overly rapid replication will cause cell lysis, tissue injury and premature host death $(A, B)$, while inadequate replication will result viral latency or clearance $(D, E)$. Viral persistence with optimal evolutionary stability requires a polymerase responsive to the host environment $(\mathrm{C})$. 
result from inadequate viral replication causing increased clearance and reduced host-to-host transmission. Viruses that cause premature host death or that are cleared by host mechanisms before transmission to, and infection of, other hosts are biological failures that have strong Darwinian pressures acting against them. Optimal long-term viral stability, therefore, dictates viral replication rates (that is, polymerase processivity) and mutation frequency (that is, polymerase fidelity) must be closely regulated (Figure 3b).

\section{Hypothesis}

That viruses capable of chronic persistence auto-regulate replication and mutation rates by replicative homeostasis. Replicative homeostasis results when RNA polymerase end-translation products (envelope and contiguously encoded accessory proteins) interact with $\mathrm{RNA}_{\mathrm{pol}}$ to alter processivity and fidelity.

\section{Evidence for Autoregulation}

Substantial clinical and in-vitro evidence, including the kinetic paradox indicate viruses auto-regulate. During successful antiviral treatment levels of virus fall sharply $[12,29,52,53,57]$, often becoming undetectable. However, viral replication rebounds, rapidly and precisely, to pre-treatment levels on drug withdrawal in patients $[52,53,57]$ and in tissue culture [1]. This in-vitro data confirm replication is controlled by factors independent of either cellular or humoral immune function. Auto-regulation of HCV replication was confirmed most emphatically in patients undergoing plasmapharesis in whom $60-90 \%$ reduction in levels of virus returned to baseline, but not beyond, within 3-6 hours of plasma exchange [44]. Studies suggesting autoregulation of tobacco mosaic virus replication occurred independent of interferon effects, intrinsic interference or interference by defective virus [34] confirming this phenomenon is not confined to either animal viruses or cells. These data beg the questions: How does the replicative mechanism "choose" any particular level of replication and how does it return, so accurately, to pre-treatment levels?

\section{RNA polymerase control}

Most cellular enzymes are under some form of kinetic control, usually by product inhibition. While simple negative-feedback product inhibition is sufficient to control enzyme reaction velocity and the rate of product synthesis, it is inadequate to ensure the functional quality of any complex molecules - including proteins - synthesised. The functionality of $\mathrm{RNA}_{\mathrm{pol}}$ output depends on the functionality of protein(s) translated from any RNA synthesized by RNApol. For viruses, and their polymerase, evolutionary survival - i.e. whether the polymerase, and its viral shell, avoids immune surveillance, gains access to cells, and replicates to infect other hosts - is a function of the properties that the sequence, topological variability and structural integrity of envelope proteins impart. RNA polymerase is responsive to and is influenced by accessory proteins that induce conformational changes to alter both processivity and fidelity [20,31], representing partial "proof of concept" of the mechanism postulated.

\section{Evolutionary stability}

Evolutionary stability requires adaptability to changing environmental circumstances. For viruses, an ability to modulate replication and mutation rates dynamically in response to cellular changes is essential. Viruses intrinsically capable of adaptation to environmental changes, including variations in host density, and evolving cell receptor polymorphisms, immune and other host responses, among other variables, will enjoy a competitive advantage over viruses lacking innate responsiveness. Contrariwise, self-replicating molecules, including viruses, that lack innate adaptability, for whom replication is contingent upon a chance confluence of appropriate cellular conditions - including permissive cell receptors, absence of cell defences and so on - are highly vulnerable to extinction by both adverse environmental changes and competition for scarce intracellular resources by molecules capable of adaptation. For viruses, this adaptability requires antigenic and structural diversity be controlled and, in turn, that means the two critical RNA $\mathrm{pol}_{\mathrm{p}}$ attributes, fidelity and processivity, be dynamically modifiable, and controllable. These linked functional requirements imply a dynamic nexus between the functional output of $\mathrm{RNA}_{\text {pol }}$ (i.e. envelope proteins) and that polymerase.

\section{Homeostatic systems}

Systems capable of homeostatic regulation (auto-regulation) have the following characteristics: i) an efferent arm that effects changes in response to perturbations of an equilibrium; ii) an afferent arm that measures the systems response to those changes; iii) mechanism(s) by which i) and ii) communicate. The mechanism of viral autoregulation - Replicative Homesostasis - described here requires: i) that viral envelope (Env) proteins interact with viral RNA polymerases $\left(\mathrm{RNA}_{\mathrm{Pol}}\right)$; ii) that these Env : $\mathrm{RNA}_{\mathrm{Pol}}$ interactions alter both polymerase processivity and fidelity; iii) that wild-type (consensus sequence) Env $_{\mathrm{wt}}: \mathrm{RNA}_{\mathrm{Pol}}$ complexes cause more rapid, less faithful RNA replication than variant (variant) $\mathrm{Env}_{\mathrm{mt}}: \mathrm{RNA}_{\mathrm{Pol}}$ complexes. There is solid evidence for each requirements of replicative homeostasis.

\section{The Envelope-Polymerase relationship: Evidence for mechanism}

A large body of literature, for many viruses, establishes an important relationship between envelope and polymerase 
proteins and documents that Env proteins influence both $\mathrm{RNA}_{\text {Pol }}$ processivity and fidelity.

First, for HIV, overwhelming evidence suggests HIV polymerases properties, and those of related retroviruses for example, simian immunodeficiency virus (SIV) and the feline immunodeficiency virus (FIV) - are influenced by Env proteins (for example, [9,15,35]. Broadly, these indicate heterologous Env proteins - when administered as live attenuated vaccines [71], adjuvant enhanced protein vaccine [83], or as recombinant Env proteins in cell culture [64] - dramatically alter viral load, and both replication and mutation rates of wild-type virus. Specific examples include data demonstrating HIV Env regions obtained from different patient isolates, when cloned into common HIV-1 backbones, conferred a spectrum of replication kinetics and cytotropisms characteristic of the original Env clone, and independent of either the clones' ability to raise antibody [51], or the replicative characteristics of the 'native' polymerase backbone [51]. Similarly, chimeric HIV-1 viruses expressing heterologous Env, again with a common polymerase backbone, have replication kinetics and cell tropism phenotypes identical to the parental Env clone [39], suggesting the Env is a critical determinant of polymerase function. Similar results obtained with SIV clones [36] strongly support conclusions drawn from feline immunodeficiency virus [37] data. Fine mapping of HIV envelope proteins identified 6 mutations within the V1-V3 loop that increased viral replication in a manner independent of nef [77], confirming other work examining HIV Env recombinants [14], and extending earlier work that demonstrated a single amino acid substitution (at position 32 of the V3 Env domain) was sufficient to change a low replication phenotype into high-replicating phenotype [13]. Finally, for HIV, co-transfection with Env variants at 10 fold excess dramatically inhibited replication of wild-type virus [75], providing direct evidence for both the interaction and differential affinity for wild-type and variant Env for polymerases. Critically, many of these observations are from in-vitro systems, indicating the effects are independent of either cellular or humoral immune influence. Many studies report the effect of Env/polymerase interactions in terms of altered viral tropisms, and did not examine changes to polymerase fidelity explicitly. However, virus replication can alter in only two ways; either there is more or less virus, or the viral genomic sequence may be changed by altered polymerase fidelity. Variant viruses expressing altered envelope proteins will have altered cell receptor affinities and hence, variable cell tropisms.

Second, for HCV, many separate observations document HCV replication and polymerase functionality is dependent on envelope proteins: i) HCV viral genotypes are defined by sequences of either envelope or polymerase regions $[43,73,74]$ and these are necessarily acquired together - a genetic nexus implying a functional relationship. ii) Observations that a) co-infection with multiple HCV genotypes occurs less frequently than predicted by chance and b) certain HCV genotypes become progressively dominant in populations both suggest - at a population level - replicative suppression of some HCV genotypes by others [68]. These observations are supported by observations of both homotypic [33] and heterotypic HCV super-infection [32] documenting genotypedependent replicative suppression of one HCV genotype by another in individual patients. iii) Functional infectious chimeric viruses with polymerase and Env proteins derived from different genotypes have not been reported. iv) Full-length HCV chimeras, engineered with deletions of p7 envelope proteins, are replication deficient and noninfections, indicating intact genotype-specific HCV envelope sequences are essential for proper HCV replication. Specific replacement of $\mathrm{p} 7$ of the 1a clone with $\mathrm{p} 7$ from an infectious genotype 2a clone was replication defective, suggesting a genotype-specific interaction between the 77 envelope protein and other genomic regions [66]. v) In two independent chimpanzees studies HCV inoculation resulted in persistent infection only in animals developing anti-envelope (E2) antibodies, whereas failure to produce anti-E2 was associated with viral clearance $[4,62]$, intuitively a highly paradoxical result difficult to rationalize unless E2 proteins are important for sustained HCV replication, as we argued previously [45]. vi) Finally, for HCV, specific motifs within the [polymerase] NS5 region of $\mathrm{HCV}$ in chronically infected patients predict response to interferon $[19,67]$ an observation that makes little sense unless interferon interacts directly with NS5 [polymerase] motifs, as in-vitro studies suggest [10].

Third, HBV envelope and polymerase protein genes have overlapping open reading frames and significant alterations in envelope and polymerase gene and protein sequences cannot, therefore, occur independently, a genetic nexus again implying an important functional relationship. Mutations in envelope sequences occurring spontaneously [82] following therapy of HBV with lamuvidine and immunoglobulin prophylaxis $[6,72]$ or after vaccine escape [8] are frequently associated with high level viral replication, although replication-deficient mutations are described [47]. These data are generally interpreted to mean polymerase gene mutation(s) cause altered polymerase protein sequence and, hence, abnormal polymerase function. While this is probably partially true if the functionally relevant HBV RNA polymerase is an envelope/polymerase heterodimer (analogous to the p66/p51heterodimer of HIV RT [30]), then an equally valid interpretation is that mutations in envelope genes may change envelope protein conformation and therefore alter normal envelope/polymerase interactions, thus 


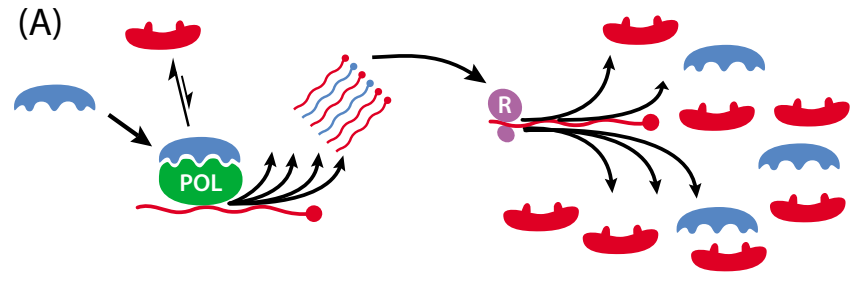

(B)

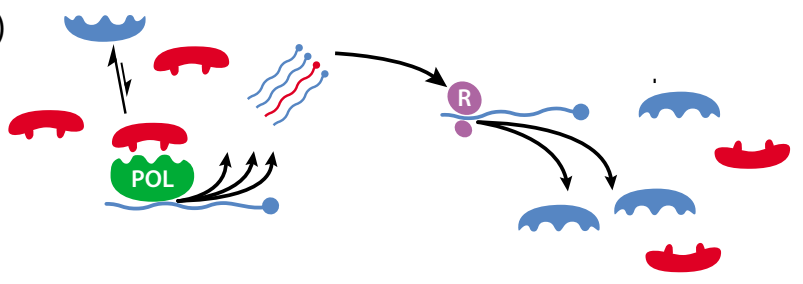

Figure 4

Mechanism of replicative homeostasis. At $A$, relatively high concentrations of $E_{n v} v_{t}$ (blue, A) favour high affinity Env:RNA $A_{p o l}$ interactions out-competing variant forms (Env $v_{m t}$, red), increasing RNA $_{\text {pol }}$ Processivity but reduced fidelity increasing relative output of variant RNAs. Subsequent ribosomal ( $R$, mauve) translation increases concentrations Env $\mathrm{mt}_{\mathrm{m}}$ (red), relative to $E n v_{W_{t}}$, returning the system to equilibrium. Relative excess $E_{n v} v_{m t}\left(B\right.$, red) out-compete $E n v_{W_{t}}$ (blue) for interactions with $\mathrm{RNA}_{\mathrm{pol}}$, favouring $\mathrm{Env}_{\mathrm{mt}}: \mathrm{RNA}_{\mathrm{pol}}$, and blocking Env ${ }_{W_{t}}: R A_{p o l}$ interactions. Env $v_{m t}: R N A_{p o l}$ complexes relatively decrease RNA $\mathrm{A}_{\text {pol }}$ processivity but increase fidelity, increasing output of wild-type RNAs. Subsequent increased translation of Env $\mathrm{Wt}_{\mathrm{t}}$ relative to $\mathrm{Env}_{\mathrm{mt}}$ restores the equilibrium.

altering processivity and fidelity of the replication complex. This latter interpretation is convincingly supported by data demonstrating that abnormal polymerase function of HBV envelope variants is reversed by co-transfection of Hep G2 cells with clones expressing wild-type envelope sequences [81] and is further supported by clinical studies demonstrating administration of exogenous HBsAg (protein) to patients with chronic HBV dramatically reduced HBV replication [60].

Fourth, studies of the coliphage $\mathrm{Q} \beta$ demonstrate phage coat proteins bind to genomic RNA [86]to strongly inhibit (association $\mathrm{K}_{\mathrm{ic}} \approx 10^{7-8} \mathrm{M}^{-1}$, inhibition $\mathrm{K}_{\mathrm{i}} \approx 10^{9} \mathrm{M}^{-1} \mathrm{~s}^{-1}$ ) [79] RNA replication by direct suppression of polymerase activity by envelope proteins [18]. This interaction is dependent on the binding site conformation, but not RNA sequence [86], suggesting interaction avidity will vary as an inverse function of protein sequence divergence from wild type, an intuitive expectation confirmed experimentally [79]. An impressive body of literature documents similar relationships between envelope and polymerase function in swine fever, tobacco mosaic [34], brome mosaic [2] and other RNA viruses. Importantly, studies of the tobacco mosaic virus confirmed this effect to be host-independent and virus-specific inhibition of viral RNA synthesis and to be quite distinct from any interferon effects, intrinsic interference or interference by defective virus [34]. Thus, there exists solid evidence for each necessary component of replicative homeostasis for $\mathrm{HCV}$, HBV and HIV, and other viruses.

\section{Replicative homeostasis: proposed mechanism}

Replicative homeosatsis results from differential interactions of wild-type $(\mathrm{Wt})$ and variant $(\mathrm{Mt})$ envelope proteins on $\mathrm{RNA}_{\mathrm{pol}}$ in a series of feedback epicycles linking $\mathrm{RNA}_{\text {pol }}$ function, RNA replication and protein synthesis (Figure 4,5). Intracellular accumulation of variant viral proteins causes progressive, direct, inhibition of $\mathrm{RNA}_{\mathrm{pol}}$ and also block $\mathrm{Env}_{\mathrm{Wt}}: \mathrm{RNA}_{\mathrm{pol}}$ interactions that increase replication and mutation. Progressive blockade of $\mathrm{RNA}_{\mathrm{pol}}$ by variant envelope results in a less processive, more faithful, polymerase, increasing the relative output of wildtype envelope RNAs, and, subsequently, translation of wild-type envelope proteins and, hence, an inexorable progression to stable equilibria. Quasispecies stability, and other consequences (including immune escape and low-level basal replication), are inevitable outcomes that result from equilibria reached because of these interactions (Figure 5). We suggest these interactions, and the resulting equilibria, are important therapeutic targets, and the effective ligands - envelope proteins or topologically homologous molecules - implicit within this hypothesis.

Viral polymerases are clearly the effector mechanism - the efferent arm - that determines rate of viral RNA replication and mutation. The afferent arm needs to measure both the rate of viral replication and degree of viral mutation. Intracellular envelope concentrations are a direct function of effective viral replication, while competition between wild-type and variant envelope proteins for interaction with $\mathrm{RNA}_{\mathrm{pol}}$ allows determination of viral mutation rates. Envelope proteins, as opposed to other viral products, are the obvious products to examine for functional variability, and must form part of the afferent arm necessary to "sense" perturbations in the viral equilibrium. While other viral products could be "sensed" to gauge effective viral replication, only functional measurement of envelope protein concentration and topological variability simultaneous measures both the rate of viral replication and envelope functions - properties determined by envelope structure and antigenic diversity essential for viral survival; immune escape and cell access. Furthermore, envelope and polymerase proteins are typically coded at transcriptionally opposite ends of the viral genome; replication contingent upon a dynamic nexus between envelope and polymerase proteins is, therefore, a 


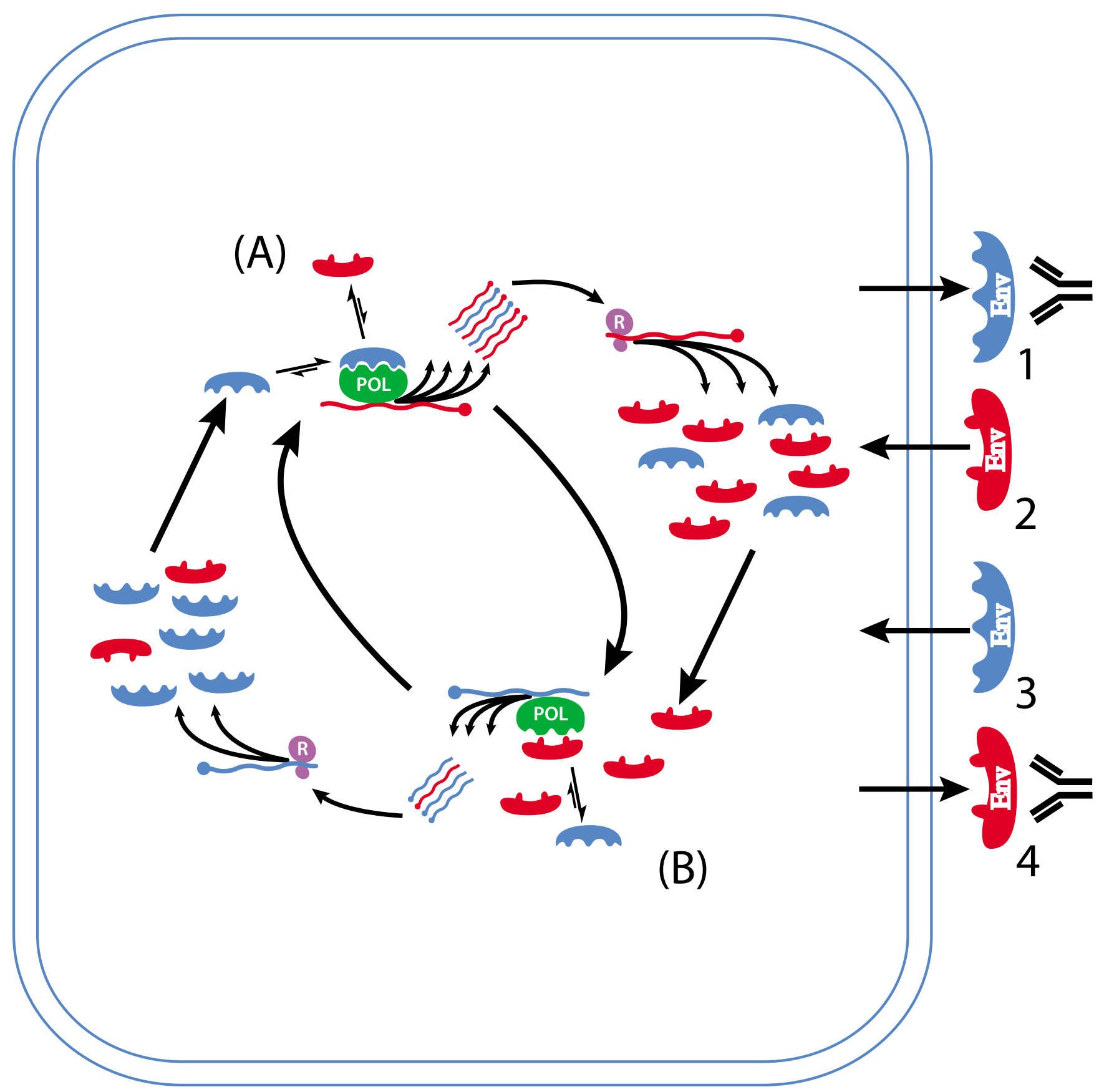

Figure 5

Conseqences of replicative homeostatic cycles. Disturbance to intracellular replicative homeostatic cycles. Events increasing intracellular Env $\mathrm{Wt}_{\mathrm{t}}$ : Env $\mathrm{mt}_{\mathrm{t}}$ ratio (exogenous addition of Env $\mathrm{Wt}_{\mathrm{t}}$, antibody recognition of Env $\mathrm{mt}_{\mathrm{t}}$ ) will favour

$E_{n v_{t}}: R^{R N} A_{p o l}$ interactions, increasing RNA $A_{p o l}$ Processivity and reducing fidelity increasing relative output of variant virus. Conversely, events decreasing intracellular Env $\mathrm{Wt}_{\mathrm{t}}$ : Env $\mathrm{mt}_{\mathrm{mt}}$ ratios (exogenous addition of Env $\mathrm{mt}_{\mathrm{t}}$, antibody recognition of Env $\mathrm{Wt}_{\mathrm{t}}$ ) will favour $\mathrm{Env}_{\mathrm{mt}}: \mathrm{RNA}_{\mathrm{pol}}$ interactions, decreasing $\mathrm{RNA}_{\mathrm{pol}}$ processivity and increasing fidelity, thus reducing replication. 
functional check of the integrity of the entire viral genome. Importantly, this facet of replicative homeostasis is a direct mechanism of Darwinian selection operating at a molecular level, that ensurs preferential selection and replication of "fit" viral genomes, and maintenance of genotypes (species).

Viruses, notably HIV, produce many accessory proteins (such as HIV Nef, gag, rev and HBeAg) that affect viral replication and mutation rate. However, these proteins are encoded within envelope open reading frames (ORFs) or are contiguous with them and are likely to alter functionally with any mutation affecting envelope sequences (Figure 6). While these accessory proteins may interact with $\mathrm{RNA}_{\text {pol }}$ (with or without Env) to reset replicative equilibrium (by changing replication rate or mutation frequency or both), stable equilibria will still result providing the sum effect of variant proteins encoded within the envelope ORF is to decrease $\mathrm{RNA}_{\text {pol }}$ processivity (v) and mutation $\left(\mathrm{M}_{\mathrm{u}}\right)$ frequency relative to wild-type protein polymerase interactions.

\section{Testing the hypothesis}

This hypothesis is simply tested. Manoeuvres that increase intracellular concentrations of variant envelope proteins or decrease wild-type envelope proteins should inhibit viral replication and reduce mutation rates. Conversely, manoeuvres increasing intracellular $\left[E v_{W t}\right]$ or reducing intracellular $\left[\mathrm{Env}_{\mathrm{mt}}\right]$ should accelerate viral replication and mutation. In fact, observations relevant to every aspect of this hypothesis have been reported in a variety of systems and circumstances. All outcomes are completely consistent with those predicted by replicative homeostasis. Replicative homeostasis predicts, for example, HCV E2 proteins derived from genotype $1 \mathrm{HCV}$ sequences would reduce HCV replication when administered to patients with heterologous HCV infection (genotypes 2,3 or 4, for example) and studies examining heterologous envelope proteins as direct $\mathrm{RNA}_{\text {pol }}$ inhibitors are underway.

\section{Discussion}

Replicative homeostasis immediately resolves the paradox RNA viral quasispecies stability and explains how these viruses persist and, thereby, cause disease. Replicative homeostasis also explains the initial decline of viral replication, resolving the kinetic paradox, rationalizing the dynamics of chronic viral infection and other enigmatic and unresolved viral behaviours. Most importantly, replicative homeostasis implies a general approach to antiviral therapy.

The equilibria formed by replicative homeostasis are responsive to disturbance of envelope concentrations ensuring viral mutation is neither random nor passive but highly reactive to external influence: Sustained reduction of viral envelope (by immune or other mechanisms) would favour high affinity $\mathrm{Env}_{\mathrm{Wt}}: \mathrm{RNA}_{\mathrm{pol}}$ interactions that, in turn, increase polymerase processivity but reduce fidelity accelerating synthesis of variant viral RNAs and, consequently, increased translation of antigenically diverse proteins, reactively driving quasispecies expansion and generating the extreme antigenic diversity of RNA quasispecies. Alternatively, in the absence of immunological recognition, variant envelope / polymerase interactions predominate, restricting viral replication and mutation, thus maintaining basal output of consensus viral sequences, thus maintaining genotype. Immune escape and maximal cell tropism are inevitable consequences of the potential antigenic diversity generated by RNA replication mediated by the reactive equilibria of replicative homeostasis.

Potential viral antigenic diversity is numerical superior to any immune response; Theoretically, a small envelope protein of 20 amino acids could assume $20^{20}$ (about 1026) possible conformations, greatly exceeding the $\sim 10^{10}$ antibody [80] or CTL receptor conformations either humoral and cellular immune responses can generate. A direct consequence of this mismatch and the stable reactive, equilibria resulting from replicative homeostasis is that once infection is established, the clinical outcome is primarily determined by the viruses' ability to maintain control of the quasispecies, rather than the hosts' response to that quasispecies. This sanguine view is supported by both general clinical experience and by kinetic analysis of chronic viral infection (Figure 2); if host responses are unable to clear virus at $10^{5-7}$ viral equivalents / $\mathrm{ml}$ they are not likely to be any more effective at $10^{8-11} \mathrm{eq} / \mathrm{ml}$.

The varied clinical outcomes of viral infections are explained by replicative homeostasis and its failure: Viral failure to down-regulate replication by $\mathrm{RNA}_{\mathrm{pol}}$ inhibition would cause rapidly progressive or fulminant disease (characterised by massively polyclonal, but ultimately ineffectual, immune responses), while inadequate replication or generation of diversity will result in viral clearance (Figure 3b). Stable, homeostatic replicative equilibria will result in chronic infection with episodic fluctuations in viral replication and host responses (eg ALT; [65]) typical of chronic hepatitis or HIV. The widely varied spectrum and tempo of viral diseases, that for viral hepatitis ranges from asymptomatic healthy chronic carriage to fulminant liver disease and death within days, is far more rationally explained on the basis of a broad spectrum of polymerase properties than highly variable and unpredictable (yet genetically homogeneous) immune responses.

Homeostatic systems functioning without external perturbations - such as thermostatically controlled water tanks - progress rapidly to stasis (Figure 7). In tissue culture, 


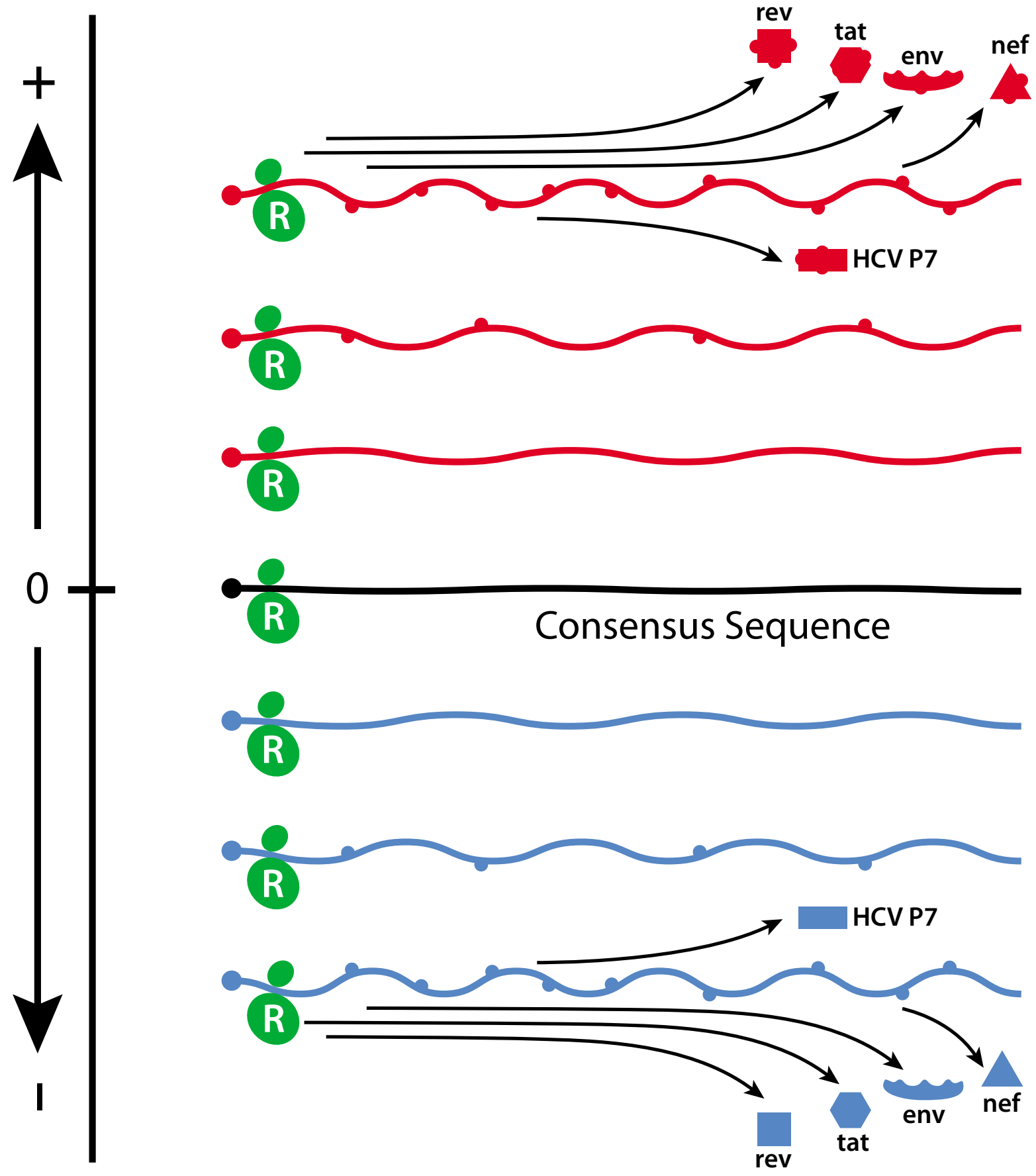

\section{Figure 6}

Phenotypic effects of RNA quasispecies complexity. Two-dimensional representation of multi-dimensional hyperdense sequence-space that define viral quasispecies; vast RNA / proteins populations progressively divergent from consensus sequence (0). As genetic the distance of RNAs increases from consensus sequence the amino acid sequence, conformation, and functional properties of resulting proteins may also change, potentially resulting in proteins that, despite originating from identical [consensus sequence] genetic domains, have diametrically opposed function. As many accessory proteins (for example, HIV rev, tat, nef and HCV HP7) have open reading frames contiguous with Envelope, sequence changes to Env will also affect accessory protein function. 


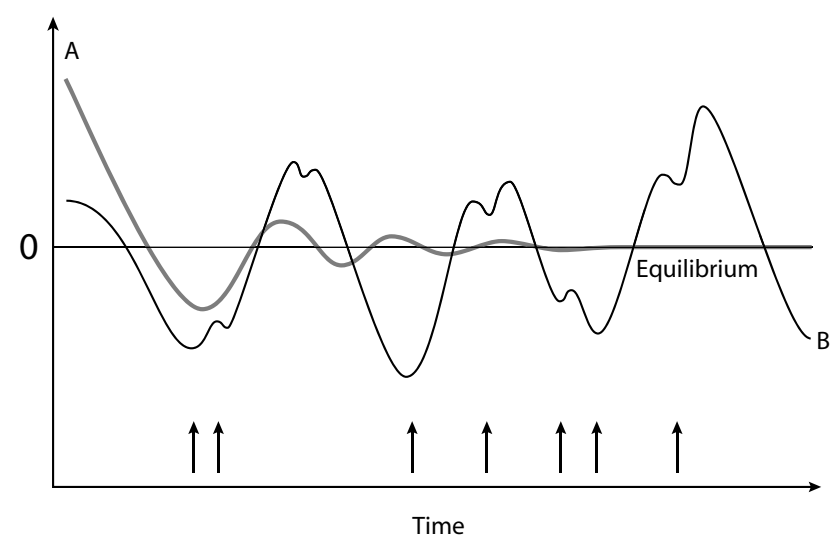

Figure 7

Homeostatic systems. In absence of external influence, homeostatic systems (A) progress rapidly to stasis (0) while external perturbations (arrows, e.g. immune recognition of virus) cause pseudo-chaotic fluctuating long-term behaviours in complex systems (B).

viruses - replicating without immune challenge - are unable (and do not need) to generate antigenic diversity by replicative homeostasis, a phenomenon probably responsible for attenuation of virulence of serially passaged virus cultures. By contrast, in dilute viral culture, where viral envelope and polymerase exist in low concentrations,

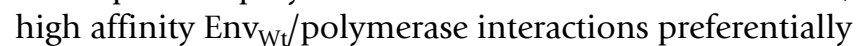
occur over lower affinity $\mathrm{Env}_{\mathrm{mt}} /$ polymerase interactions, replicative homeostasis predicts increased viral replication and mutation would occur and this has been confirmed [70]

Perturbations of relative intracellular wild-type and variant envelope concentrations alter $\mathrm{RNA}_{\mathrm{pol}}$ : Env interactions disturbing the replicative equilibria of replicative homeostasis. Antibodies (or CTL) will alter extracellular concentrations of Env proteins, thus changing intracellular envelope concentrations once extracellular /intracellular Env concentrations equilibrate. Therefore, antibodies to heterologous envelope proteins - developing, for example, during immunization against other viruses or heterotypic co-infection - will reduce relative intracellular concentrations of variant envelope, favouring $\mathrm{RNA}_{\mathrm{pol}}: \mathrm{Env}_{\mathrm{Wt}}$ interactions, thus enhancing replication and increasing mutation rates, a prediction confirmed in practice $[38,56]$. Contrariwise, antibodies to wild-type surface proteins - for example, during administration of anti-HBsAb following liver transplantation for HBV [63] would reduce viral replication (Figure 6), as seen in practice. Disturbance of viral replicative equlibria by heterologous extracellular antibodies rationally explains antibodydependent enhancement (ADE) of HIV [23], Dengue
[26], Murray Valley encephalitis[84], Ebola [78] Coxsackie [24] and other viruses. Similarly, increased HIV replication and mutation after influenza [38] or tetanus [56] vaccination; reduced HIV replication during measles [50] and Dengue [85] co-infection; clearance of HBV without hepatocyte lysis or evidence of $\mathrm{T}$ cell dependent cytotoxicity[25], are also explained by this mechanism. Previously unexplained and problematic viral behaviours and host responses, including long-term non-progression of HIV [7]; persistence of transcriptionally active HBV despite a robust immune response [48]; long-term antigenic oscillations [54]; spontaneous reactivation of HBV[41] (among many other viruses); and hypermutation of HIV, for example, all rationally resolve within this conceptual framework.

There are clear and quite specific therapeutic implications of replicative homeostasis, as well as more general implications. The envelope/polymerase interactions of replicative homeostasis suggested herein are obvious therapeutic targets, and a site of interferon action: Heterologous envelope proteins from different viruses or genotypes of the same virus, or their structural homologues, are likely to inhibit viral replication, as suppression of HIV replication during measles [50] and Dengue [85] co-infection suggests. Interferon is ineffective for HIV and many patients with HBV, and its efficacy in HCV is highly genotypedependent, strongly implying a direct, virus-specific action unrelated to "immune enhancement", as in-vitro data [10] and clinical kinetic studies imply [52]. Complexing of interferon to $\mathrm{RNA}_{\mathrm{pol}}$ to reduce processivity and increase fidelity would explain both the genotype specificity of interferon action and the kinetics of action and, incidentally, the apparent "immune enhancement" [59] caused by interferon; if interferon reduces $\mathrm{RNA}_{\text {pol }}$ processivity while increasing its fidelity, viral RNAs synthesized will contain fewer mutations causing synthesis of antigenically restricted proteins, thus presenting a more homogeneous target susceptible to immune attack.

Replicative homeostasis may alter perceptions of strategies underpinning the immune responses. It is possible the primary purpose of the initial polymorphic humoral response to viral infection - typically pentameric IgM - is to push viral replication towards equilibria favouring production of homogeneous virus, thus facilitating a concerted and more focussed humoral and/or cytotoxic $\mathrm{T}$ cell response; Strong neutralizing IgG antibodies - antiH$\mathrm{BsAg}$, for example - may develop as a consequence of initially restricted viral replication and mutation permitting effective and specific immune recognition, rather than being the proximate cause of it. The temporal profile of HBsAb, that develops well after HBVreplication falls, strongly supports this view. However, once developed, high-affinity neutralizing antibodies against wild-type 
virus ensure variant envelope proteins remain dominant within cells, thus maximising polymerase inhibition and inhibiting viral replication.

Replicative homeostasis is an adaptation that facilitates stable viral replication in cells and maximises probability of cell-to-cell (and host-to-host) transmission, a prerequisite for viral survival on an evolutionary time scale (Figure 3 ). A subtle, more primordial, and evolutionary function of envelope/polymerase interactions may explain the origins of replicative homeostasis; Polymerase function contingent upon recognition of, and response to, complex three-dimensional complementarities between polymerase and envelope proteins constitutes a sophisticated encryption technique, effectively "locking" the polymerase, thereby minimises the likelihood any competing RNA (or DNA) molecules are replicated even if correct 5' transcription initiation sequences are present. This is, again, a powerful mechanism of selection, speciation and genotype preservation. As Spiegleman suggested originally [55], in the fierce competition for finite intracellular resources, reproductive strategies that maximise proliferation of "self" genes, while thwarting propagation of "rival" genes, are strongly selected for, and are highly conserved in evolution. The interferons, and other cytokines, are cellular defence mechanisms that long antedate the immune system. If the interferons are functionally homologous to viral envelope proteins, and interact with viral RNApol to reduce processivity and replication to restrict viral replication and antigenic diversity, increasing their susceptibility to immune clearance, it is possible these genes were acquired as result of positive selection of beneficial virus-cell symbiosis occurring early in eukaryotic cellular evolution, a process responsible for retention of other genes [28].

Although proposed specifically to explain RNA viral quasispecies stability, replicative homeostasis is, fundamentally, a mechanism that regulates RNA transcription and modulates protein expression. If proteins (i.e. phenotype) modulate $\mathrm{RNA}_{\mathrm{pol}}$ properties (in a manner contingent on that proteins functionality) and modulate mutations introduced into the RNA templates $\mathrm{RNA}_{\text {pol }}$ synthesises, a subtle form of "quality control" is exerted over protein synthesis [69]. This mechanism accelerates, and directs, adaptation: While introduction of lethal mutations to most RNA genomes may not adversely influence quasispecies, replicative homeostasis ensures any RNA mutations that do arise, and that result in beneficial phenotype(s), will favour replication of that RNA molecule, ensuring that phenotype is retained within the quasispecies. Minor change to polymerase fidelity will profoundly effect a quasispecies; as Haldane demonstrated [27], a reproductive advantage of only $0.1 \%$ is sufficient to increase a gene frequency from $0.1 \%$ to $50 \%$ over a few thousand generations ( $\sim 1$ year for the average patient with HCV) and this effect, therefore, represents a major moulding force in evolution. Thus, replicative homeostasis provides a powerful counterbalance to Muller's ratchet [17] and, by promoting retention and transmission of acquired phenotype, is a Lamarkian mechanism fully consistent with Darwinian principles and operative at a molecular level.

Finally, accessory proteins that alter the processivity and fidelity of both DNA-dependent RNA polymerases [31] and DNA-dependent DNA polymerases [42] to modulate polymerases activity are strongly conserved in evolution, suggesting a critical cellular function. Control of DNAdependent $\mathrm{RNA}_{\mathrm{pol}}$ transcription by DNA viruses, cellular micro-organisms (e.g. malaria), and eukaryotic cells, subtly modulating cell-surface protein expression, via replicative homeostasis, to mediate immune escape, control cell division and differentiation, or other functions would not be surprising.

\section{Acknowledgements}

I thank Professors WD Reed, MG McCall, RA Joske, Bill Musk, AE Jones and Jay Hoofnagle for critical clinical and scientific guidance and SJ Coleman, Matt and Tim for everything else.

\section{References}

I. Abdelhamed AM, Kelley CM, Miller TG, Furman PA, Isom HC: Rebound of hepatitis $B$ virus replication in HepG2 cells after cessation of antiviral treatment. J Virol 2002, 76:8|48-60.

2. Ahlquist $P$, Dasgupta R, Kaesberg $P$ : Nucleotide sequence of the brome mosaic virus genome and its implications for viral replication. J Mol Biol 1984, I 72:369-83.

3. Ahmad N, Venkatesan S: Nef protein of HIV-I is a transcriptional repressor of HIV-I LTR. Science 1988, 24I:|48|-5.

4. Bassett SE, Guerra B, Brasky K, Miskovsky E, Houghton M, Klimpel GR, Lanford RE: Protective immune response to hepatitis $C$ virus in chimpanzees rechallenged following clearance of primary infection. Hepatology 2001, 33:1479-87.

5. Bertoletti A, Ferrari C: Kinetics of the immune response during HBV and HCV infection. Hepatology 2003, 38:4-I3.

6. Bock CT, Tillmann HL, Torresi J, Klempnauer J, Locarnini S, Manns MP, Trautwein C: Selection of hepatitis B virus polymerase mutants with enhanced replication by lamivudine treatment after liver transplantation. Gastroenterology 2002, I 22:264-73.

7. Cao Y, Qin L, Zhang L, Safrit J, Ho DD: Virologic and immunologic characterization of long-term survivors of human immunodeficiency virus type I infection. N Engl J Med 1995 , 332:201-8.

8. Carman WF, Zanetti AR, Karayiannis P, Waters J, Manzillo G, Tanzi E, Zuckerman AJ, Thomas HC: Vaccine-induced escape mutant of hepatitis B virus. Lancet 1990, 336:325-9.

9. Chen M, Shi C, Kalia V, Tencza SB, Montelaro RC, Gupta P: HIV gp I $20 \mathrm{~V}(1) / \mathrm{V}(2)$ and $\mathbf{C ( 2 ) - V ( 3 )}$ domains glycoprotein compatibility is required for viral replication. Virus Res 2001 , 79:91-I0I.

10. Chung RT, He W, Saquib A, Contreras AM, Xavier RJ, Chawla A, Wang TC, Schmidt EV: Hepatitis C virus replication is directly inhibited by IFN-alpha in a full-length binary expression system. Proc Natl Acad Sci U S A 2001, 98:9847-52.

II. Coffin JM: HIV population dynamics in vivo: implications for genetic variation, pathogenesis, and therapy. Science 1995, 267:483-9.

12. Daar ES, Moudgil T, Meyer RD, Ho DD: Transient high levels of viremia in patients with primary human immunodeficiency virus type I infection. N Engl J Med I99I, 324:96 I-4. 
13. De Jong J], De Ronde A, Keulen W, Tersmette M, Goudsmit J: Minimal requirements for the human immunodeficiency virus type I V3 domain to support the syncytium-inducing phenotype: analysis by single amino acid substitution. J Virol 1992 , 66:6777-80

14. De Jong J], Goudsmit J, Keulen W, Klaver B, Krone W, Tersmette M, de Ronde A: Human immunodeficiency virus type I clones chimeric for the envelope $V 3$ domain differ in syncytium formation and replication capacity. I Virol 1992, 66:757-65.

15. DeStefano J]: Interaction of human immunodeficiency virus nucleocapsid protein with a structure mimicking a replication intermediate. Effects on stability, reverse transcriptase binding, and strand transfer. J Biol Chem 1996, 27 I: I6350-6.

16. Drake JW, Holland Jj: Mutation rates among RNA viruses. Proc Natl Acad Sci U S A 1999, 96:13910-3.

17. Duarte E, Clarke D, Moya A, Domingo E, Holland J: Rapid fitness losses in mammalian RNA virus clones due to Muller's ratchet. Proc Natl Acad Sci U S A 1992, 89:60I 5-9.

18. Eigen M: Viral quasispecies. Sci Am 1993, 269:42-9.

19. Enomoto N, Sakuma I, Asahina Y, Kurosaki M, Murakami T, Yamamoto C, Ogura Y, Izumi N, Marumo F, Sato C: Mutations in the nonstructural protein $5 \mathrm{~A}$ gene and response to interferon in patients with chronic hepatitis $\mathbf{C}$ virus $\mathbf{I b}$ infection. N Engl J Med 1996, 334:77-8I.

20. Erie DA, Hajiseyedjavadi O, Young MC, von Hippel PH: Multiple RNA polymerase conformations and GreA: control of the fidelity of transcription. Science 1993, 262:867-73.

21. Fackler OT, d'Aloja P, Baur AS, Federico M, Peterlin BM: Nef from human immunodeficiency virus type I(FI2) inhibits vira production and infectivity. J Virol 200I, 75:660I-8.

22. Farci P, Alter HJ, Govindarajan S, Wong DC, Engle R, Lesniewski RR, Mushahwar IK, Desai SM, Miller RH, Ogata N, et al.: Lack of protective immunity against reinfection with hepatitis $\mathbf{C}$ virus. Science 1992, 258: I35-40.

23. Fust G: Enhancing antibodies in HIV infection. Parasitology 1997, I I 5(Suppl):SI 27-40.

24. Girn J, Kavoosi M, Chantler J: Enhancement of coxsackievirus B3 infection by antibody to a different coxsackievirus strain. J Gen Virol 2002, 83:35I-8.

25. Guidotti LG, Rochford R, Chung J, Shapiro M, Purcell R, Chisari FV: Viral clearance without destruction of infected cells during acute HBV infection. Science 1999, 284:825-9.

26. Guzman MG, Kouri G, Halstead SB: Do escape mutants explain rapid increases in dengue case-fatality rates within epidemics? Lancet 2000, 355:1902-3.

27. Haldane J: The Causes of Evolution. Princeton University Press, New Jersey; 1932.

28. Hedges SB, Chen H, Kumar S, Wang DY, Thompson AS, Watanabe $\mathrm{H}$ : A genomic timescale for the origin of eukaryotes. BMC Evol Biol 200I, I:4.

29. Ho DD, Neumann AU, Perelson AS, Chen W, Leonard JM, Markowitz M: Rapid turnover of plasma virions and CD4 lymphocytes in HIV-I infection. Nature 1995, 373:123-6.

30. Jacobo-Molina A, Arnold E: HIV reverse transcriptase structurefunction relationships. Biochemistry 1991, 30:635I-6.

3I. Jeon C, Agarwal K: Fidelity of RNA polymerase II transcription controlled by elongation factor TFIIS. Proc Natl Acad Sci U S A 1996, 93:13677-82.

32. Kao JH, Chen PJ, Lai MY, Chen DS: Superinfection of heterologous hepatitis $\mathbf{C}$ virus in a patient with chronic type $\mathbf{C}$ hepatitis. Gastroenterology 1993, 105:583-7.

33. Kao JH, Chen PJ, Wang JT, Yang PM, Lai MY, Wang TH, Chen DS Superinfection by homotypic virus in hepatitis $C$ virus carriers: studies on patients with post-transfusion hepatitis. J Med Virol 1996, 50:303-8

34. Kiho $Y$, Nishiguchi $M$ : Unique nature of an attenuated strain of tobacco mosaic virus: autoregulation. Microbiol Immunol 1984, 28:589-99.

35. Kirchhoff F, Mori K, Desrosiers RC: The "V3" domain is a determinant of simian immunodeficiency virus cell tropism. J Virol 1994, 68:3682-92.

36. Kirchhoff F, Morrison HG, Murray MG, Rennert P, Desrosiers RC SIVmac expressing hybrid envelope proteins containing HIV-I V3 and/or C4 sequences is not competent for replication. AIDS Res Hum Retroviruses 1994, 10:309-13.
37. Kohmoto M, Miyazawa T, Tomonaga K, Kawaguchi Y, Mori T, Tohya Y, Kai C, Mikami T: Comparison of biological properties of feline immunodeficiency virus isolates using recombinant chimeric viruses. J Gen Virol I994, 75(Pt 8): 1935-42.

38. Kolber MA, Gabr AH, De La Rosa A, Glock JA, Jayaweera D, Miller N, Dickinson GM: Genotypic analysis of plasma HIV-I RNA after influenza vaccination of patients with previously undetectable viral loads. Aids 2002, 16:537-42.

39. Kuwata T, Shioda T, Igarashi T, Ido E, Ibuki K, Enose Y, Stahl-Hennig C, Hunsmann G, Miura T, Hayami M: Chimeric viruses between SIVmac and various HIV-I isolates have biological properties that are similar to those of the parental HIV-I. Aids 1996, I0: $|33|-7$.

40. Lazaro E, Escarmis C, Perez-Mercader J, Manrubia SC, Domingo E: Resistance of virus to extinction on bottleneck passages: study of a decaying and fluctuating pattern of fitness loss. Proc Natl Acad Sci U S A 2003, 100:10830-5.

4I. Lok AS, Lai CL, Wu PC, Leung EK, Lam TS: Spontaneous hepatitis $B$ e antigen to antibody seroconversion and reversion in Chinese patients with chronic hepatitis B virus infection. Gastroenterology 1987, 92: 1839-43.

42. Maga G, Frouin I, Spadari S, Hubscher U: Replication protein A as a "fidelity clamp" for DNA polymerase alpha. J Biol Chem 200I, 276: $18235-42$.

43. Mahaney K, Tedeschi V, Maertens G, Di Bisceglie AM, Vergalla J, Hoofnagle JH, Sallie R: Genotypic analysis of hepatitis $\mathbf{C}$ virus in American patients. Hepatology 1994, 20: I 405-II.

44. Manzin A, Candela M, Solforosi L, Gabrielli A, Clementi M: Dynamics of hepatitis $C$ viremia after plasma exchange. J Hepatol 1999, $31: 389-93$.

45. Marrone A, Sallie R: Genetic heterogeneity of hepatitis $\mathbf{C}$ virus. The clinical significance of genotypes and quasispecies behavior. Clin Lab Med 1996, 16:429-49.

46. McCright IJ, Tsunoda I, Whitby FG, Fujinami RS: Theiler's viruses with mutations in loop I of VPI lead to altered tropism and pathogenesis. J Virol 1999, 73:28|4-24.

47. Melegari M, Scaglioni PP, Wands JR: Hepatitis B virus mutants associated with 3TC and famciclovir administration are replication defective. Hepatology 1998, 27:628-33.

48. Michalak TI, Pasquinelli C, Guilhot S, Chisari FV: Hepatitis B virus persistence after recovery from acute viral hepatitis. J Clin Invest 1994, 93:230-9.

49. Miller MD, Warmerdam MT, Gaston I, Greene WC, Feinberg MB The human immunodeficiency virus-I nef gene product: a positive factor for viral infection and replication in primary lymphocytes and macrophages. J Exp Med 1994, 179:101-13.

50. Moss W], Ryon J], Monze M, Cutts F, Quinn TC, Griffin DE: Suppression of human immunodeficiency virus replication during acute measles. J Infect Dis 2002, 185: 1035-42.

5I. Mustafa F, Richmond JF, Fernandez-Larsson R, Lu S, Fredriksson R, Fenyo EM, O'Connell M, Johnson E, Weng J, Santoro JC, Robinson HL: HIV-I Env glycoproteins from two series of primary isolates: replication phenotype and immunogenicity. Virology 1997, 229:269-78.

52. Neumann AU, Lam NP, Dahari H, Gretch DR, Wiley TE, Layden TJ, Perelson AS: Hepatitis $C$ viral dynamics in vivo and the antiviral efficacy of interferon-alpha therapy. Science 1998, 282: 103-7.

53. Nevens F, Main J, Honkoop P, Tyrrell DL, Barber J, Sullivan MT, Fevery J, De Man RA, Thomas HC: Lamivudine therapy for chronic hepatitis B: a six-month randomized dose-ranging study. Gastroenterology 1997, I I3:1258-63.

54. Nowak MA, May RM, Phillips RE, Rowland-Jones S, Lalloo DG, McAdam S, Klenerman P, Koppe B, Sigmund K, Bangham CR, et al: Antigenic oscillations and shifting immunodominance in HIV-I infections. Nature 1995, 375:606-II.

55. Oehlenschlager F, Eigen M: $\mathbf{3 0}$ years later--a new approach to Sol Spiegelman's and Leslie Orgel's in vitro evolutionary studies. Dedicated to Leslie Orgel on the occasion of his 70th birthday. Orig Life Evol Biosph 1997, 27:437-57.

56. Ostrowski MA, Krakauer DC, Li Y, Justement SJ, Learn G, Ehler LA, Stanley SK, Nowak M, Fauci AS: Effect of immune activation on the dynamics of human immunodeficiency virus replication and on the distribution of viral quasispecies. J Virol 1998, 72:7772-84 
57. Perelson AS, Neumann AU, Markowitz M, Leonard JM, Ho DD: HIV. I dynamics in vivo: virion clearance rate, infected cell lifespan, and viral generation time. Science 1996, 27 I: 1582-6.

58. Piatak M Jr, Saag MS, Yang LC, Clark SJ, Kappes JC, Luk KC, Hahn BH Shaw GM, Lifson JD: High levels of HIV-I in plasma during all stages of infection determined by competitive PCR. Science 1993, 259: I 749-54.

59. Poaty-Mavoungou V, Toure FS, Tevi-Benissan C, Mavoungou E: Enhancement of natural killer cell activation and antibodydependent cellular cytotoxicity by interferon-alpha and interleukin-12 in vaginal mucosae Sivmac25I-infected Macaca fascicularis. Viral Immunol 2002, 15:197-2I2.

60. Pol S: Immunotherapy of chronic hepatitis B by anti HBV vaccine. Biomed Pharmacother 1995, 49:105-9.

6I. Preston BD, Poiesz BJ, Loeb LA: Fidelity of HIV-I reverse transcriptase. Science 1988, 242: I |68-7|

62. Prince AM, Brotman B, Lee DH, Ren L, Moore BS, Scheffel JW: Significance of the anti-E2 response in self-limited and chronic hepatitis $C$ virus infections in chimpanzees and in humans. J Infect Dis 1999, I80:987-9I.

63. Pruett TL, McGory R: Hepatitis B immune globulin: the US experience. Clin Transplant 2000, I 4(Suppl 2):7-13.

64. Quesada-Rolander M, Makitalo B, Thorstensson R, Zhang $Y$ ], Castanos-Velez E, Biberfeld G, Putkonen P: Protection against mucosal SIVsm challenge in macaques infected with a chimeric SIV that expresses HIV type I envelope. AIDS Res Hum Retroviruses 1996, 12:993-9.

65. Ribeiro RM, Layden-Almer J, Powers KA, Layden TJ, Perelson AS: Dynamics of alanine aminotransferase during hepatitis $C$ virus treatment. Hepatology 2003, 38:509-17.

66. Sakai A, Claire MS, Faulk K, Govindarajan S, Emerson SU, Purcell RH, Bukh J: The $\mathbf{p 7}$ polypeptide of hepatitis $\mathbf{C}$ virus is critical for infectivity and contains functionally important genotypespecific sequences. Proc Natl Acad Sci U S A 2003, 100: | 1646-5I.

67. Sakuma I, Enomoto N, Kurosaki M, Marumo F, Sato C: Selection of hepatitis $C$ virus quasispecies during interferon treatment. Arch Virol 1996, 141:1921-32.

68. Sallie R: Hepatitis C: IIb (IV) or not IIb (IV) that is the question. Hepatology 1995, 22:67I-4.

69. Sallie R: Transcriptional homeostasis: a mechanism of protein quality control. Med Hypotheses 2004, 63:232-4.

70. Sanchez-Palomino S, Rojas JM, Martinez MA, Fenyo EM, Najera R, Domingo E, Lopez-Galindez C: Dilute passage promotes expression of genetic and phenotypic variants of human immunodeficiency virus type I in cell culture. J Virol 1993, 67:2938-43.

71. Shibata R, Siemon C, Czajak SC, Desrosiers RC, Martin MA: Live, attenuated simian immunodeficiency virus vaccines elicit potent resistance against a challenge with a human immunodeficiency virus type I chimeric virus. J Virol 1997, 7I:8I4I-8.

72. Shields PL, Owsianka A, Carman WF, Boxall E, Hubscher SG, Shaw J, O'Donnell K, Elias E, Mutimer DJ: Selection of hepatitis B surface "escape" mutants during passive immune prophylaxis following liver transplantation: potential impact of genetic changes on polymerase protein function. Gut 1999, 45:306-9.

73. Simmonds $P$, Holmes EC, Cha TA, Chan SW, McOmish F, Irvine B, Beall E, Yap PL, Kolberg J, Urdea MS: Classification of hepatitis C virus into six major genotypes and a series of subtypes by phylogenetic analysis of the NS-5 region. J Gen Virol 1993 74(Pt I I):239I-9.

74. Simmonds P, McOmish F, Yap PL, Chan SW, Lin CK, Dusheiko G, Saeed AA, Holmes EC: Sequence variability in the $\mathbf{5}^{\prime}$ non-coding region of hepatitis $C$ virus: identification of a new virus type and restrictions on sequence diversity. J Gen Virol 1993, 74(Pt 4):66I-8.

75. Steffy KR, Wong-Staal F: Transdominant inhibition of wild-type human immunodeficiency virus type 2 replication by an envelope deletion mutant. J Virol 1993, 67:1854-9.

76. Steinhauer DA, Domingo E, Holland Jj: Lack of evidence for proofreading mechanisms associated with an RNA virus polymerase. Gene 1992, 122:28I-8.

77. Su L, Kaneshima H, Bonyhadi ML, Lee R, Auten J, Wolf A, Du B, Rabin L, Hahn BH, Terwilliger E, McCune JM: Identification of HIVdeterminants for replication in vivo. Virology 1997, 227:45-52.

78. Takada A, Watanabe S, Okazaki K, Kida H, Kawaoka Y: Infectivityenhancing antibodies to Ebola virus glycoprotein. J Virol 200I, 75:2324-30.
79. Talbot SJ, Goodman S, Bates SR, Fishwick CW, Stockley PG: Use of synthetic oligoribonucleotides to probe RNA-protein interactions in the MS2 translational operator complex. Nucleic Acids Res 1990, 18:3521-8.

80. Tonegawa S: Somatic generation of antibody diversity. Nature 1983, 302:575-8I.

8I. Torresi J, Earnest-Silveira L, Civitico G, Walters TE, Lewin SR, Fyfe J, Locarnini SA, Manns M, Trautwein C, Bock TC: Restoration of replication phenotype of lamivudine-resistant hepatitis B virus mutants by compensatory changes in the "fingers" subdomain of the viral polymerase selected as a consequence of mutations in the overlapping S gene. Virology 2002, 299:88-99.

82. Tran A, Kremsdorf D, Capel F, Housset C, Dauguet C, Petit MA, Brechot C: Emergence of and takeover by hepatitis B virus (HBV) with rearrangements in the pre-S/S and pre-C/C genes during chronic HBV infection. J Virol I99I, 65:3566-74.

83. Voss G, Manson K, Montefiori D, Watkins DI, Heeney J, Wyand M, Cohen J, Bruck C: Prevention of disease induced by a partially heterologous AIDS virus in rhesus monkeys by using an adjuvanted multicomponent protein vaccine. J Virol 2003, 77:1049-58.

84. Wallace MJ, Smith DW, Broom AK, Mackenzie JS, Hall RA, Shellam GR, McMinn PC: Antibody-dependent enhancement of Murray Valley encephalitis virus virulence in mice. J Gen Virol 2003 , 84: $1723-8$.

85. Watt $G$, Kantipong $P$, Jongsakul K: Decrease in human immunodeficiency virus type I load during acute dengue fever. Clin Infect Dis 2003, 36:1067-9.

86. Witherell GW, Uhlenbeck OC: Specific RNA binding by $\mathbf{Q}$ beta coat protein. Biochemistry 1989, 28:7I-6.

Publish with Biomed Central and every scientist can read your work free of charge

"BioMed Central will be the most significant development for disseminating the results of biomedical research in our lifetime. "

Sir Paul Nurse, Cancer Research UK

Your research papers will be:

- available free of charge to the entire biomedical community

- peer reviewed and published immediately upon acceptance

- cited in PubMed and archived on PubMed Central

- yours - you keep the copyright 